\title{
ANNOUNCEMENT \\ Change in Date for Twenty-Third Annual Meeting of the Psychonomic Society
}

The twenty-third annual meeting of the Psychonomic Society will be held at the Hyatt Regency Hotel in Minneapolis, Minnesota, Thursday-Saturday, November 11-13, 1982. Members will be sent a call for papers in May 1982. Programs and hotel reservation cards will be mailed in late summer.

\section{COGNITIVE PSYCHOLOGISTS}

The Psychology Department at the University of Rochester invites cognitive psychologists at all levels of experience to apply for two tenured or tenure-track positions beginning in September 1982. Preference will be given to applicants with research interests in the areas of memory, representation, and language. These positions are part of an expanding program in cognitive science involving interaction with the faculty of other departments in both teaching and research. Potential candidates should send a résumé, a brief summary of their research interests, several representative publications, and the names and addresses of three references to David A. Taylor, Department of Psychology, University of Rochester, Rochester, New York 14627. The University of Rochester is an equal-opportunity employer; women and members of minority groups are encouraged to apply. 